\title{
Anaerobic osteomyelitis associated with intraosseous and soft-tissue pneumatosis
}

\author{
Jae Sung Son • Joong Bae Seo
}

Received: 5 March 2009/Revised: 19 March 2009/Accepted: 13 April 2009/Published online: 27 May 2009

(C) Springer-Verlag 2009

\section{Introduction}

A 13-year-old girl with paraplegia from a traffic accident presented to our hospital with fever and swelling of the left thigh for 1 month. Initial laboratory findings revealed leukocytosis, elevated C-reactive protein $(31 \mathrm{mg} / \mathrm{dl})$ and increased creatinine $(2.38 \mathrm{mg} / \mathrm{dl})$. A plain radiograph of the left hip and CT showed gas within the femur head, iliac bone and surrounding soft tissue, and extensive soft-tissue

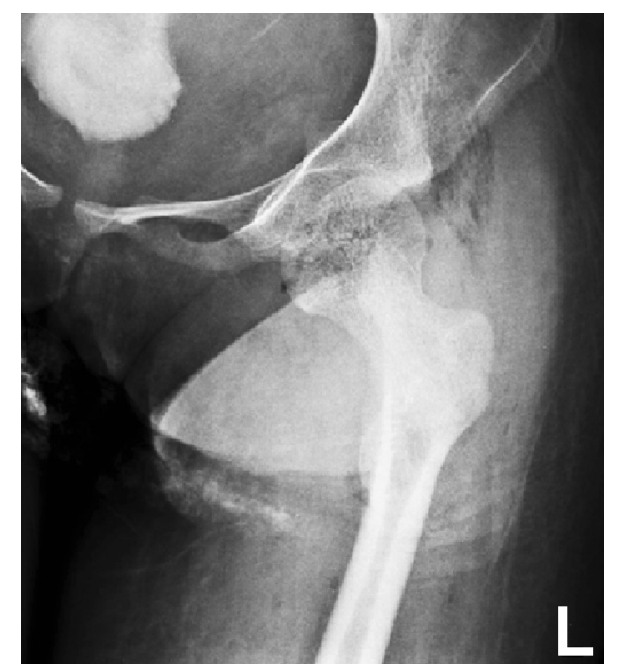

Fig. 1 Anteroposterior plain radiograph

\section{J. S. Son $(\bowtie)$}

Department of Pediatrics, College of Medicine,

Konkuk University,

4-12 Hwayang-dong, Gwangjin-gu,

Seoul, Korea

e-mail: drsonped@hanmail.net

\section{J. B. Seo}

Department of Orthopedic Surgery, College of Medicine,

Dankook University,

San-29 Anseo-Dong, Cheonan,

Choongnam, Korea



Fig. 2 Axial CT image

swelling in the pelvis, hip joint and thigh (Figs. 1 and 2). Surgical debridement and drainage of the soft-tissue abscess were performed. Cultures of both the abscess and the femoral head grew Bacteroides fragilis, B. thetaiotaomicron and Fusobacterium necrophorum.

Intraosseous gas was first detected by CT in 1981 when reported in three cases of polymicrobial osteomyelitis [1]. This condition is extremely rare, particularly in the absence of a compound fracture, surgery or other direct communication between the bone and air [2]. The pathogens are often polymicrobial and anaerobic. The presumed mechanism for the formation of intraosseous gas involves anaerobic metabolism with the production of hydrogen and carbon dioxide [2]. Anaerobic osteomyelitis can become fulminant and invasive.

\section{References}

1. Ram PC, Martinez S, Korobkin M et al (1981) CT detection of intraosseous gas: a new sign of osteomyelitis. AJR 137:721-723

2. Potocki J, Kaushik S, Mira JL (2003) Anaerobic osteomyelitis of femoral head with intraosseous, intra-articular, bursal and muscle pneumatosis. Skeletal Radiol 32:46-48 